\title{
Holdup and Flow Behavior of Fluidized Solid Particles in a Liquid-Solid Circulating Fluidized Bed
}

\author{
Dae Ho Lim, Ho Lim, Hae Ryong Jin and Yong Kang ${ }^{\dagger}$ \\ Department of Chemical Engineering, Chungnam National University, 220 Gung-dong, Yuseong-gu, Daejeon 305-764, Korea \\ (Received 11 March 2014; Received in revised form 15 April 2014; accepted 19 April 2014)
}

\begin{abstract}
Characteristics of holdup and flow behavior of fluidized solid particles were investigated in a liquid-solid circulating fluidized bed $(0.102 \mathrm{~m} \times 3.5 \mathrm{~m})$. Effects of liquid velocity $\left(\mathrm{U}_{L}\right)$, particle size $\left(\mathrm{d}_{P}\right)$ and solid circulation rate $\left(\mathrm{G}_{S}\right)$ on the solid holdup, overall particle rising velocity, slip velocity between liquid and particles and hydrodynamic energy dissipation rate in the riser were examined. The particle holdup increased with increasing $\mathrm{d}_{P}$ or $\mathrm{G}_{S}$ but decreased with increasing $\mathrm{U}_{L}$. The overall particle rising velocity increased with increasing $\mathrm{U}_{L}$ or $\mathrm{G}_{S}$ but decreased with increasing

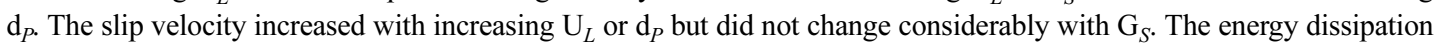
rate, which was found to be closely related to the contacting frequency of micro eddies, increased with increasing $\mathrm{d}_{P}, \mathrm{G}_{S}$ or $\mathrm{U}_{L}$. The solid particle holdup was well correlated with operating variables such as $\mathrm{U}_{L}, \mathrm{~d}_{P}$ and $\mathrm{G}_{S}$.
\end{abstract}

Key words: Liquid-solid, Circulating Fluidized Bed, Holdup, Slip Velocity, Particle Velocity, Energy Dissipation Rate

\section{Introduction}

Due to the highly effective contacting between liquid phase and fluidized solid particles, the liquid-solid fluidized bed has been widely utilized for heterogeneous flow reactors and processes such as hydrocracking using catalyst, separation or recovery processes by using ion exchange resin, adsorption, absorption and sedimentation processes [1-3]. It has been understood that the heat transfer and liquid-solid mass transfer coefficients in liquid-solid fluidized beds are extensively high while the pressure drop is extremely low, compared with other multiphase flow processes such as fixed bed reactors. Those characteristics are mainly ascribed to the flow behavior of solid particles, since the solid particles comprise a discrete phase in the continuous liquid medium [1-5]. However, the liquid-solid fluidized bed has been restricted in its usage when the solid particles are small or porous and their density is small, since the liquid velocity should be adjusted in the range between the minimum and terminal velocities of fluidized particles. In addition, the demand for small and porous solid particles has recently tended to enormously increase in the various kinds of industries.

The liquid-solid circulating fluidized bed has been proposed to overcome the disadvantages of the conventional liq-

\footnotetext{
${ }^{\dagger}$ To whom correspondence should be addressed.

E-mail: kangyong@cnu.ac.kr

This article is dedicated to Prof. Kyun Young Park on the occasion of his retirement from Kongju National Univerisity.

This is an Open-Access article distributed under the terms of the Creative Commons Attribution Non-Commercial License (http://creativecommons.org/licenses/bync/3.0) which permits unrestricted non-commercial use, distribution, and reproduction in any medium, provided the original work is properly cited.
}

uid-solid fluidized beds [6-12]. It can be operated with high liquid velocity to increase the production or operation efficiency per unit cross-sectional area of the column, by adopting the circulation mode of solid particles. It can minimize the dead zone and increase the contacting efficiency between the particles fluidized in the liquid medium, as well as between the particles and the liquid medium. The liquid-solid circulating fluidized bed can be operated in the relatively high range of liquid velocity, which leads to the increase in the shear stress at the interface between the heterogeneous phases [13-15].

The unique features of liquid-solid circulating fluidized beds can stem from the contacting motion and flow behavior of fluidized solid particles; however, there has been little attention to the flow behavior of particles. We, thus, investigated the holdup and flow behavior of fluidized solid particles in the riser of a liquid-solid circulating fluidized bed. The overall particle rising velocity, slip velocity between the liquid and solid particles and energy dissipation rate in the riser of the liquid-solid circulating fluidized bed were also examined.

\section{Experiments}

Experiments were performed in the riser of a liquid-solid circulating fluidized bed, which was composed of three main sections such as riser column, downcomer and solid recycle device, as shown Fig. 1. The details of experimental apparatus can be seen elsewhere $[11,12]$. The diameter and height of the main riser column were $0.102 \mathrm{~m}$ and $3.5 \mathrm{~m}$, respectively. A perforated plate which was installed at the bottom of the riser was used as a liquid distributor. The solid particles which 


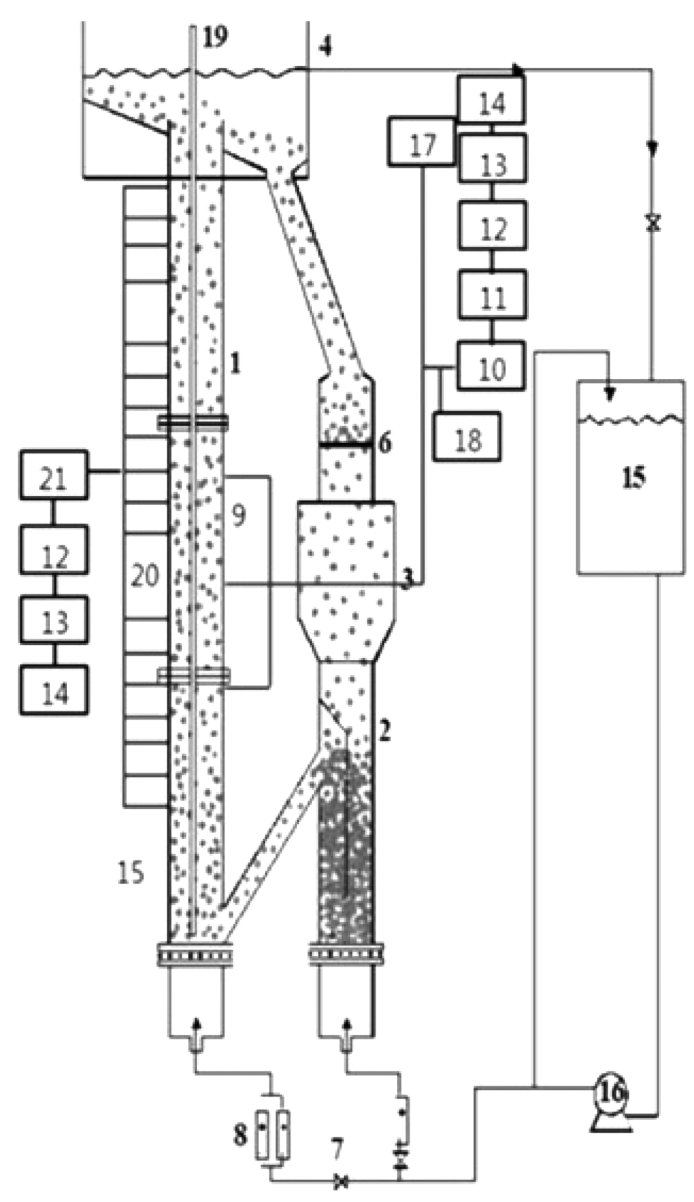

Fig. 1. Experimental apparatus.
1. Riser
2. Down Comer
12. Data acquisition system
3. Hopper
13. A/D Converter
4. L/S Separator
5. Liquid reservoir
14. Computer
15. Liquid Distributor
16. Liquid Pump
17. Power Supply
6. Butterfly Valve
18. Temperature Indicator
19. Heater
20. Pressure Tap
8. Flow meter
21. Pressure sensor
10. Amplifier
11. Low-pass Filter

were separated at the top of the riser were returned to the bottom of it through the solid recycle device. The solid particles were circulated by adjusting the angle and length of the solid recycle guide and secondary liquid flow rate at the solid recycle device. The solid circulation rate $\left(G_{S}\right)$ was determined by measuring the amounts of particles piled up above the butterfly valve in the downcomer $[11,12]$. The diameter of the glass beads was either $0.5,1.0,2.0$ or $3.0 \times 10^{-3} \mathrm{~m}$ and density was $2500 \mathrm{~kg} / \mathrm{m}^{3}$ which were used as a solid particle phase. Tap water of which density and surface tension was $1000 \mathrm{~kg} / \mathrm{m}^{3}$ and $72.75 \times 10^{-3} \mathrm{~N} / \mathrm{m}$, respectively, was used as a continuous liquid phase.

The holdup of solid particles in the riser was determined by means of the static pressure drop method with the measured values of pressure drop in the section of the riser, by using Eqs. (1) and (2) [1-4]. The pressure drops in the riser were measured by using pressure taps mounted flash with the wall of the riser in a interval of $0.15 \mathrm{~m}$ from the particle recycle port. The multi-channel pressure sensor which was connected with the pressure taps was semiconductor type (Sensys). The voltagetime signals, corresponding to the pressure-time signals, were processed by a data acquisition system (NI cDAQ-9205) and a personal computer at a rate of $1000 \mathrm{~Hz}$. The total sample length was longer than 30,000 data [16-19].

$$
\begin{aligned}
& \varepsilon_{L}+\varepsilon_{S}=1.0 \\
& \left(\varepsilon_{L} \rho_{L}+\varepsilon_{S} \rho_{S}\right) g=\Delta \mathrm{P} / \mathrm{L}
\end{aligned}
$$

\section{Results and Discussion}

Effects of liquid velocity on the solid particle holdup in the riser of liquid-solid circulating fluidized bed can be seen in Fig. 2, where the particle holdup decreases with increasing liquid velocity. The variation of solid holdup with respect to the liquid velocity is similar to that of Atta et al. [6], although the values of solid holdup are different owing to the different operating conditions. The variation of solid holdup is ascribed to the fact that the liquid holdup increases with increasing liquid velocity; thus, the particle holdup decreases to compensate for the increase in the liquid holdup. The increase of liquid velocity leads to the increase in the impact force acting on the fluidized solid particles, which promotes the entrainment of particles from the riser. Therefore, the particle holdup decreases with

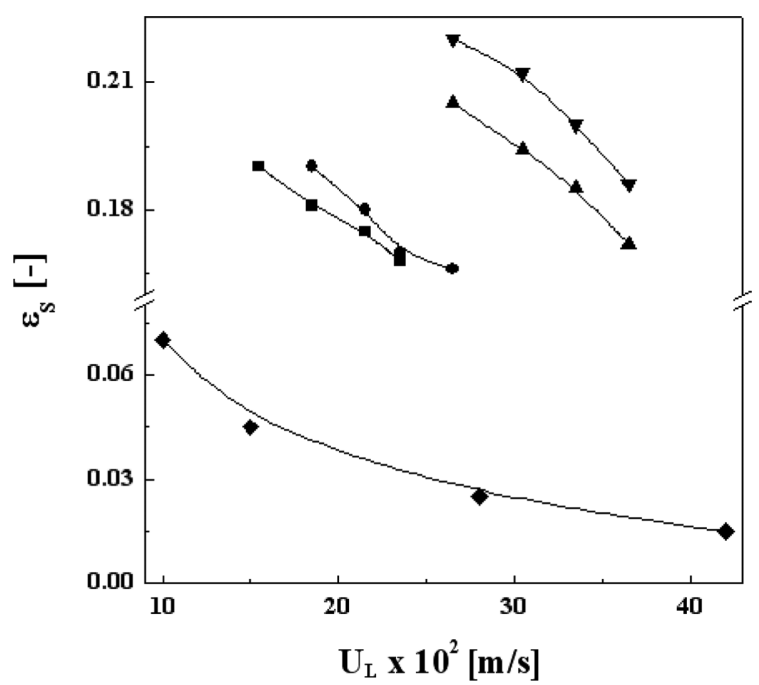

\begin{tabular}{|c|c|c|c|c|c|}
\hline $\mathrm{d}_{P} \times 10^{3}[\mathrm{~m}]$ & 0.5 & 1.0 & 2.0 & 2.0 & 0.5 \\
\hline $\mathrm{G}_{S}\left[\mathrm{~kg} / \mathrm{m}^{2} \cdot \mathrm{s}\right]$ & 6.0 & 4.0 & 4.0 & 6.0 & 10.0 \\
\hline $\mathrm{D}[\mathrm{m}]$ & 0.102 & 0.102 & 0.102 & 0.102 & 0.076 \\
\hline
\end{tabular}

Fig. 2. Effects of $U_{L}$ on $\varepsilon_{s}$ in liquid-solid circulating fluidized beds. 


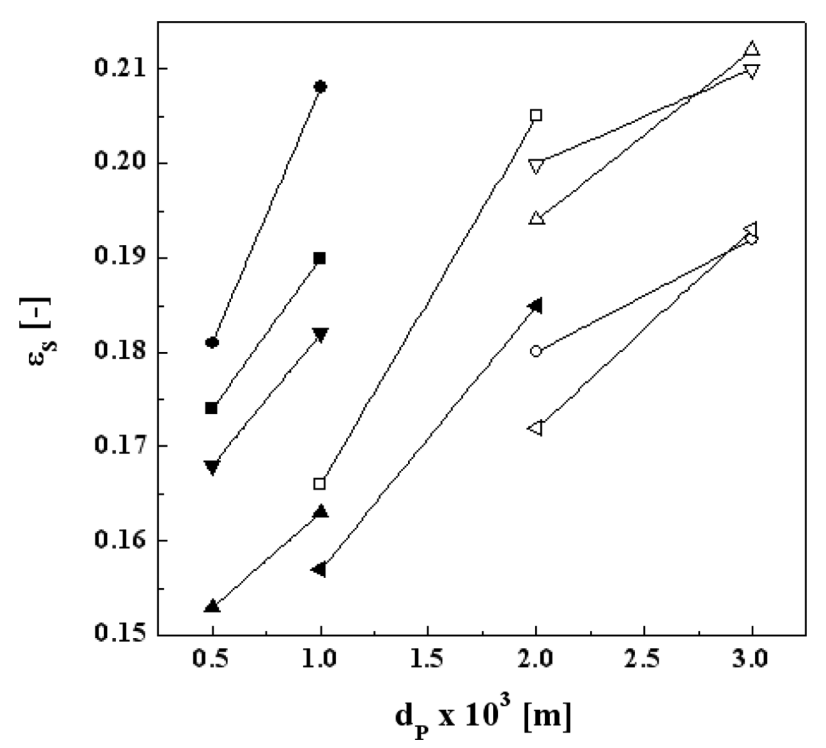

Fig. 3. Effects of $d_{P}$ on $\varepsilon_{s}$ in liquid-solid circulating fluidized beds.

$\begin{array}{ccccccccccc}\mathrm{U}_{L} \times 10^{2}[\mathrm{~m} / \mathrm{s}] & \mathbf{D} & \bullet & \boldsymbol{\Delta} & \boldsymbol{\nabla} & \boldsymbol{4} & \square & \bigcirc & \triangle & \nabla & \triangleleft \\ 18.5 & 23.5 & 23.5 & 26.5 & 26.5 & 30.5 & 30.5 & 33.5 & 36.5\end{array}$

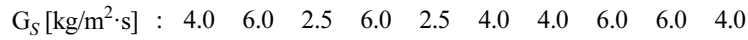

increasing liquid velocity. However, the decrease of particle holdup is not severe compared with that in the conventional liquid-solid fluidized beds [1-4], since the particles are circulated continuously. Effects of particle size on the particle holdup in the riser can be seen in Fig. 3, where the particle holdup increases with increasing particle size. This is because the terminal velocity increases with increasing particle size. In other words, the amount of particles entrained from the riser decreases with increasing particle size. Therefore, the amount of solid particles fluidized in the riser increases with increasing $\mathrm{d}_{P}$. Effects of solid circulation rate on the particle holdup in the riser can be seen in Fig. 4. In this figure, the value of particle holdup increases with increasing solid circulation rate, which is similar to the results of Atta et al. [6]. The solid circulation rate has been defined as weight of solid particles injected into and entrained from the riser per unit time and cross-sectional area of the riser. Therefore, the increase of solid circulation rate means the increase of solid amount injected into the riser; thus, the solid holdup increases with increasing $\mathrm{G}_{\mathrm{S}}$ in all the cases studied.

It has been understood that the overall flow behavior of particles in the riser is one of the important factors in the design of the liquid-solid circulating fluidized bed reactor or contactor and to predict the performance of it [13-15]. The overall interstitial rising velocity of solid particles in the riser can be obtained by Eq. (3), which can be used to predict and analyze the particle flow behavior in the riser.

$$
\mathrm{U}_{S}=\frac{\mathrm{G}_{S}}{\rho_{S} \varepsilon_{S}}
$$

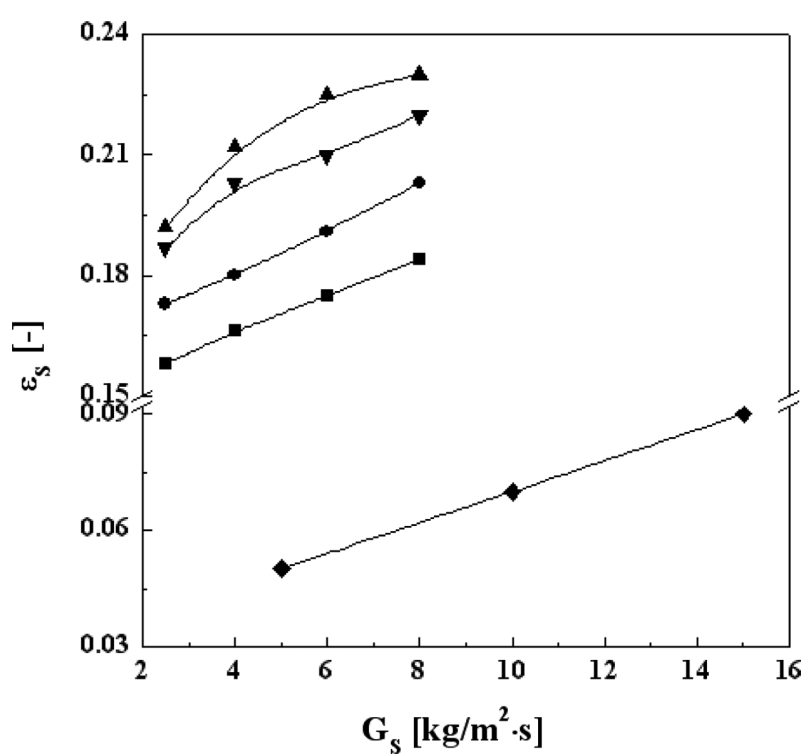

Fig. 4. Effects of $G_{S}$ on $\varepsilon_{s}$ in liquid-solid circulating fluidized beds.
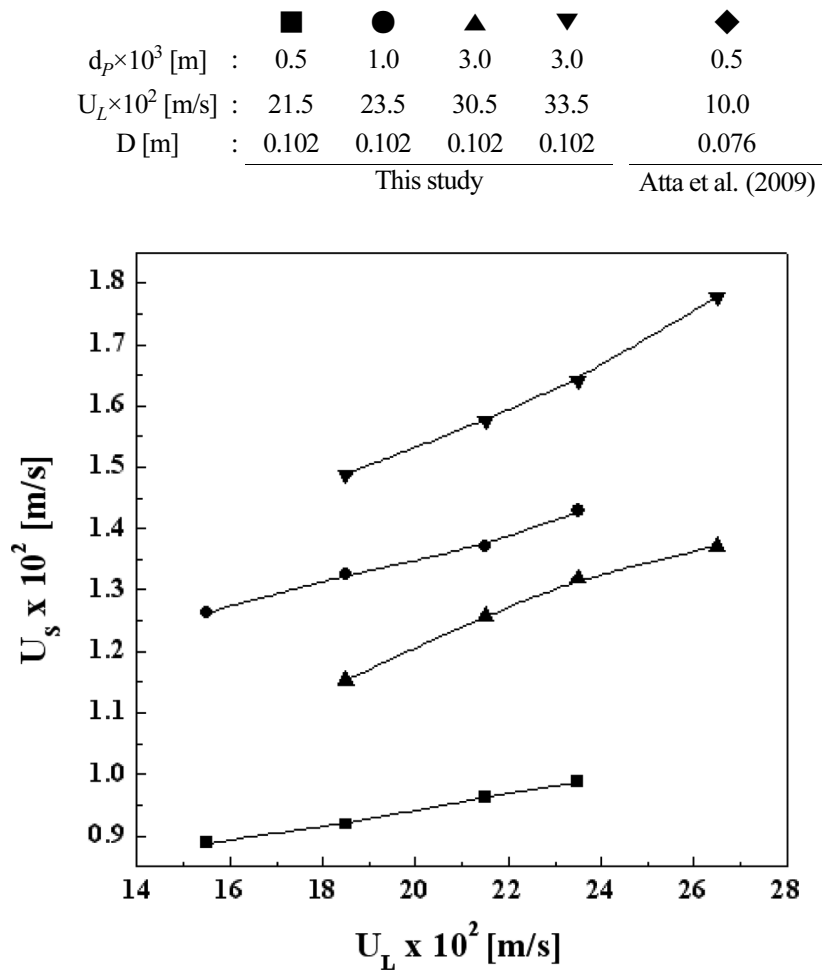

Fig. 5. Effects of $U_{L}$ on $U_{S}$ in liquid-solid circulating fluidized beds.

$\begin{array}{cccccc} & & \boldsymbol{\square} & \boldsymbol{0} & \boldsymbol{\Delta} & \boldsymbol{\nabla} \\ \mathrm{d}_{P} \times 10^{3}[\mathrm{~m}] & : & 0.5 & 0.5 & 1.0 & 1.0 \\ \mathrm{G}_{S}\left[\mathrm{~kg} / \mathrm{m}^{2} \cdot \mathrm{s}\right] & : & 4.0 & 6.0 & 6.0 & 8.0\end{array}$

Effects of liquid velocity, particle size and solid circulation rate on the overall particle rising velocity in the riser, $\mathrm{U}_{S}$, can be seen in Figs. 5 and 6. In Fig. 5, the overall particle rising velocity increases with increasing liquid velocity, which is due to the increase of upward fluidizing force acting on the particles by liquid flow. The overall particle rising velocity also increases with increasing solid circulation rate, but it decreases 


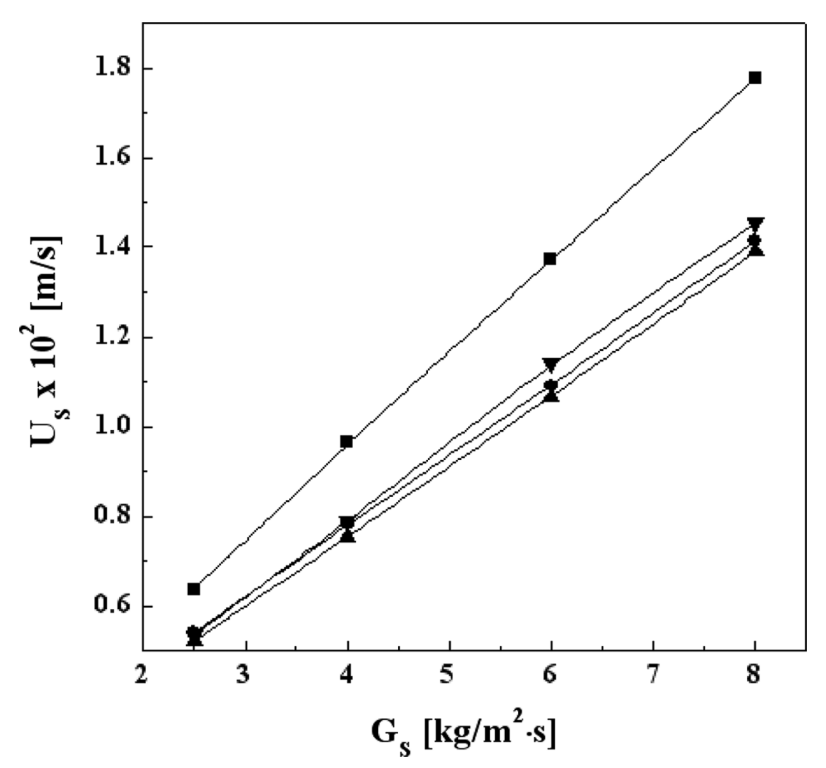

Fig. 6. Effects of $G_{S}$ on $U_{S}$ in liquid-solid circulating fluidized beds.

\begin{tabular}{|c|c|c|c|c|}
\hline & $\square$ & 0 & $\Delta$ & $\nabla$ \\
\hline $\mathrm{U}_{L} \times 10^{2}[\mathrm{~m} / \mathrm{s}]$ & 26.5 & 26.5 & 30.5 & 33.5 \\
\hline $\mathrm{d}_{P} \times 10^{3}[\mathrm{~m}]$ & 1.0 & 2.0 & 3.0 & 3.0 \\
\hline
\end{tabular}

with increasing particle size (Figs. 5 and 6). Although the particle holdup increases with increasing solid circulation rate, the effect of solid circulation rate is dominant rather than particle holdup on the overall particle rising velocity; thus, the value of particle rising velocity increases with increasing solid circulation rate. It can be expected that the particle velocity decreases with increasing particle size, since the weight of particles increases with increasing $d_{P}$ in a given solid circulation rate condition.

Since the flow rate of continuous liquid medium and that of discrete solid particles in the riser are different from each other, the slip velocity between them can be defined as Eq. (4).

$$
\mathrm{U}_{\text {Slip }}=\frac{\mathrm{U}_{L}}{\left(1-\varepsilon_{S}\right)}-\mathrm{U}_{S}
$$

It has been understood that the relative velocity between the continuous liquid phase and the discrete solid particles could create shear stress and force at the interface during flow, which is directly related to the mass and heat transfer between them and in the flow process [6-12]. Effects of particle size, solid circulation rate and liquid velocity on the slip velocity, $\mathrm{U}_{\text {Slip }}$, can be seen in Figs. 7 and 8. The slip velocity increases with increasing particle size and liquid velocity. However, the effect of solid circulation rate on the slip velocity is marginal, as can be seen in Fig. 8. As mentioned earlier, the particle holdup (Fig. 4) and overall particle rising velocity (Fig. 6) increase with increasing solid circulation rate. Therefore, the effects of

Korean Chem. Eng. Res., Vol. 52, No. 3, June, 2014

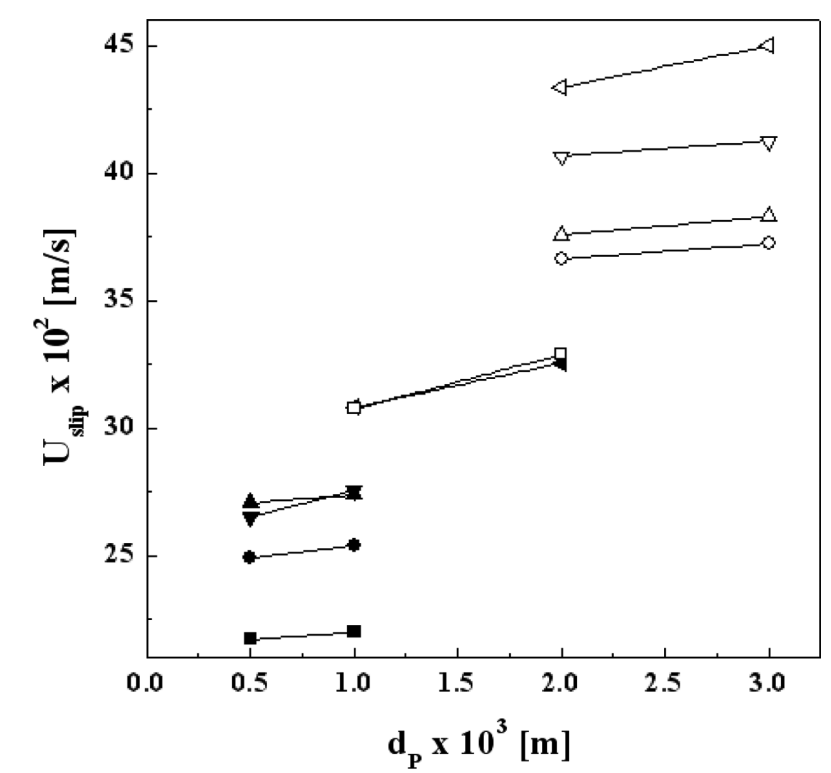

Fig. 7. Effects of $d_{P}$ on $\mathbf{U}_{\text {slip }}$ in liquid-solid circulating fluidized beds.

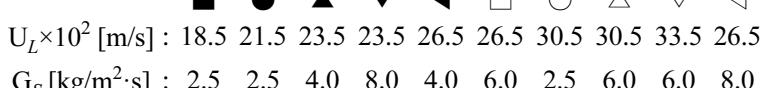

solid circulation rate on both of particle holdup and slip velocity in Eq. (4) could compensate each other; thus, the value of slip velocity does not change considerably with variation of solid circulation rate.

The overall turbulence phenomenon in the riser, which is due to the fluidization of particles in the continuous flow of liquid phase, can be predicted by means of the hydrodynamic energy dissipation. The energy input rate per unit weight of continuous liquid phase can be written as Eq. (5). In addition, the energy recovery rate by means of flowing liquid and entrained particles from the top of the riser can be written as Eq. (6).

$$
\begin{aligned}
& \mathrm{E}_{I}=\frac{\mathrm{U}_{L}\left(\varepsilon_{L} \rho_{L}+\varepsilon_{S} \rho_{S}\right) \mathrm{g}}{\varepsilon_{L} \rho_{L}} \\
& \mathrm{E}_{R}=\frac{\left(\mathrm{U}_{L} \rho_{L}+\mathrm{G}_{S}\right) \mathrm{g}}{\varepsilon_{S} \rho_{L}}
\end{aligned}
$$

Then, the energy dissipation rate can be obtained as Eqs. (7) and (8) in the riser of liquid-solid circulating fluidized beds.

$$
\begin{aligned}
& \mathrm{E}_{D}=\mathrm{E}_{I}-\mathrm{E}_{R} \\
& \mathrm{E}_{D}=\frac{\left[\mathrm{U}_{L}\left(1-\varepsilon_{L}\right)\left(\rho_{S}-\rho_{L}\right)-\mathrm{G}_{S}\right] \mathrm{g}}{\varepsilon_{L} \rho_{L}}
\end{aligned}
$$

Effects of particle size, solid circulation rate and liquid velocity on the hydrodynamic energy dissipation rate in the riser can be seen in Figs. 9 and 10. The energy dissipation rate increases with increasing particle size, solid circulation rate and liquid velocity. This can be ascribed to the fact that the 


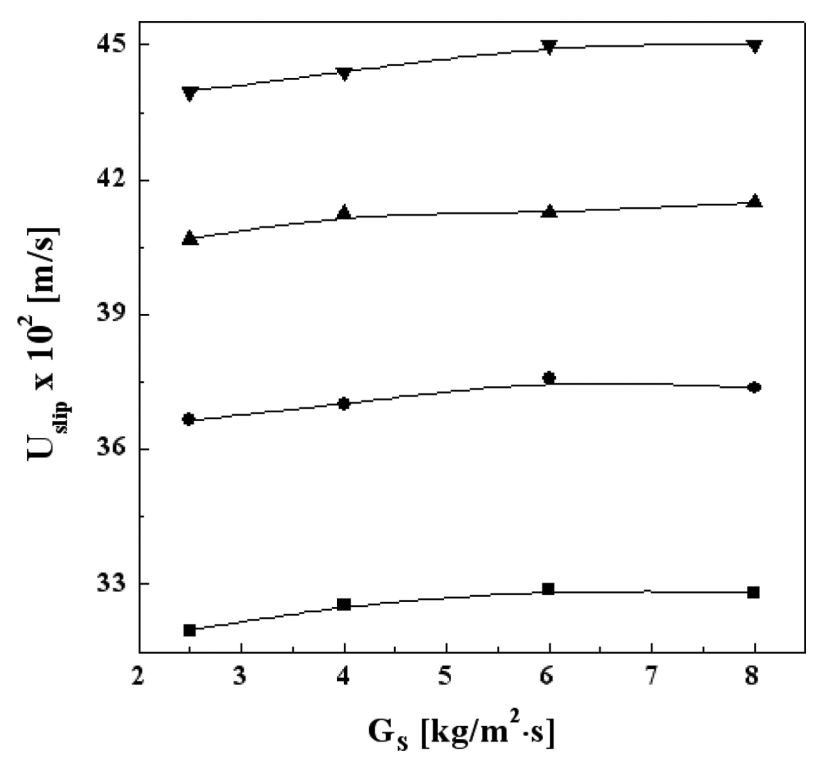

Fig. 8. Effects of $\mathrm{G}_{S}$ on $\mathrm{U}_{\text {slip }}$ in liquid-solid circulating fluidized beds.

\begin{tabular}{|c|c|c|c|c|}
\hline & & & $\Delta$ & $\nabla$ \\
\hline $\mathrm{d}_{P} \times 10^{3}[\mathrm{~m}]$ & 2.0 & 2.0 & 3.0 & 3.0 \\
\hline $\mathrm{U}_{L} \times 10^{2}[\mathrm{~m} / \mathrm{s}]$ & 26.5 & 30.5 & 33.5 & 36.5 \\
\hline
\end{tabular}

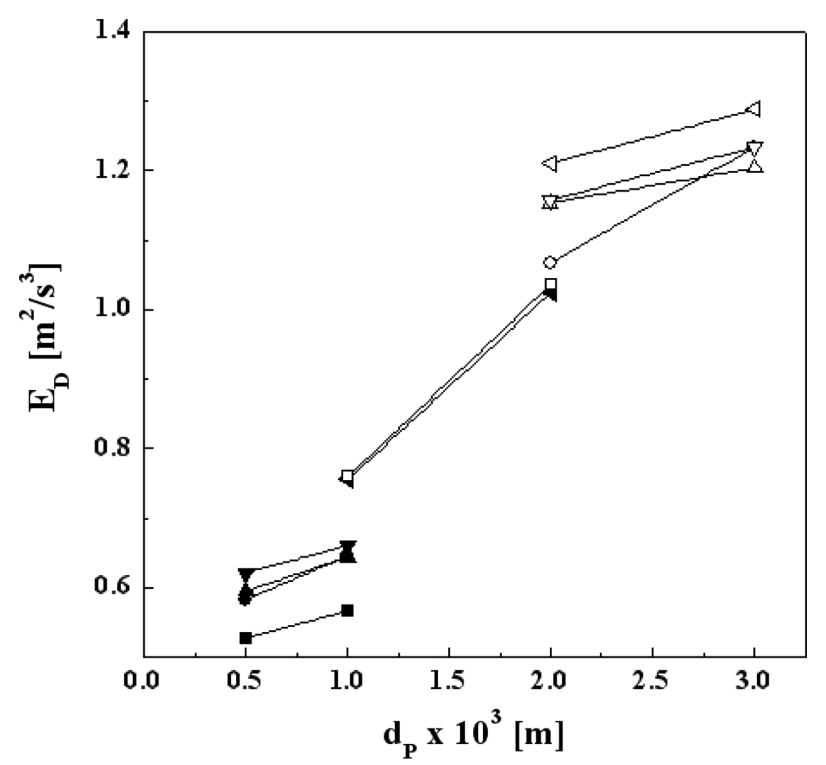

Fig. 9. Effects of $d_{P}$ on $E_{D}$ in liquid-solid circulating fluidized beds.

$\mathrm{U}_{L} \times 10^{2}[\mathrm{~m} / \mathrm{s}]: 18.521 .523 .523 .526 .526 .530 .530 .533 .533 .5$ $\mathrm{G}_{\mathrm{S}}\left[\mathrm{kg} / \mathrm{m}^{2} \cdot \mathrm{s}\right] \quad: \quad \begin{array}{llllllllll}2.5 & 4.0 & 2.5 & 4.0 & 6.0 & 8.0 & 4.0 & 6.0 & 6.0 & 8.0\end{array}$

increase of particle size, solid circulation rate or liquid velocity leads to the increase of turbulence in the riser. That is, the interaction and contacting between liquid and solid particles as well as among solid particles could increase with increasing $\mathrm{d}_{p}, \mathrm{G}_{s}$ and $\mathrm{U}_{L}$. The turbulent interaction and contacting can be expressed by adopting the surface renewal theory based on the concept of local isotropic turbulence model [22,23]. The energy dissipation in the turbulent flow field can be related to

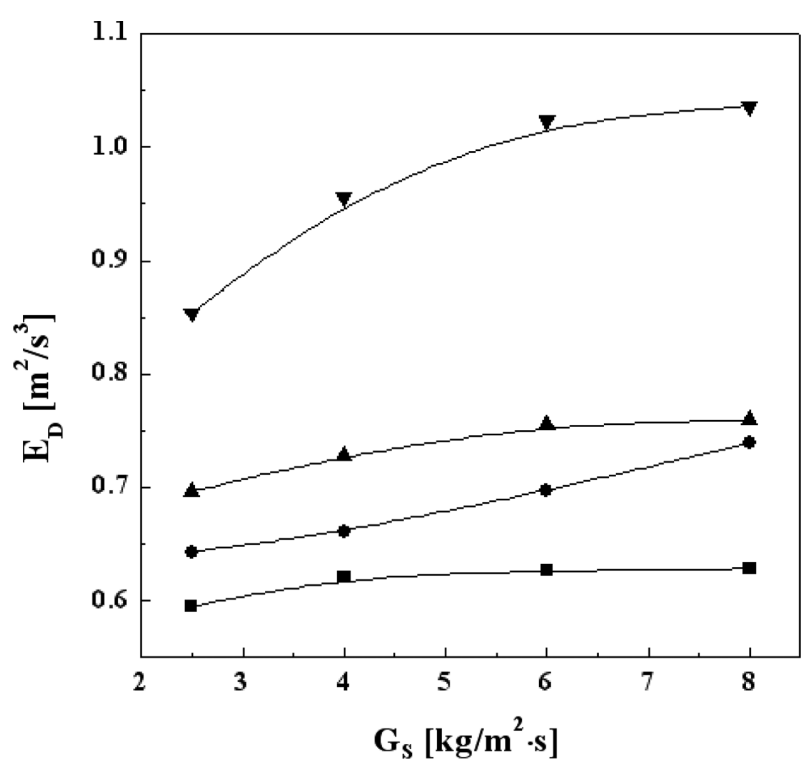

Fig. 10. Effects of $G_{S}$ on $E_{D}$ in liquid-solid circulating fluidized beds.
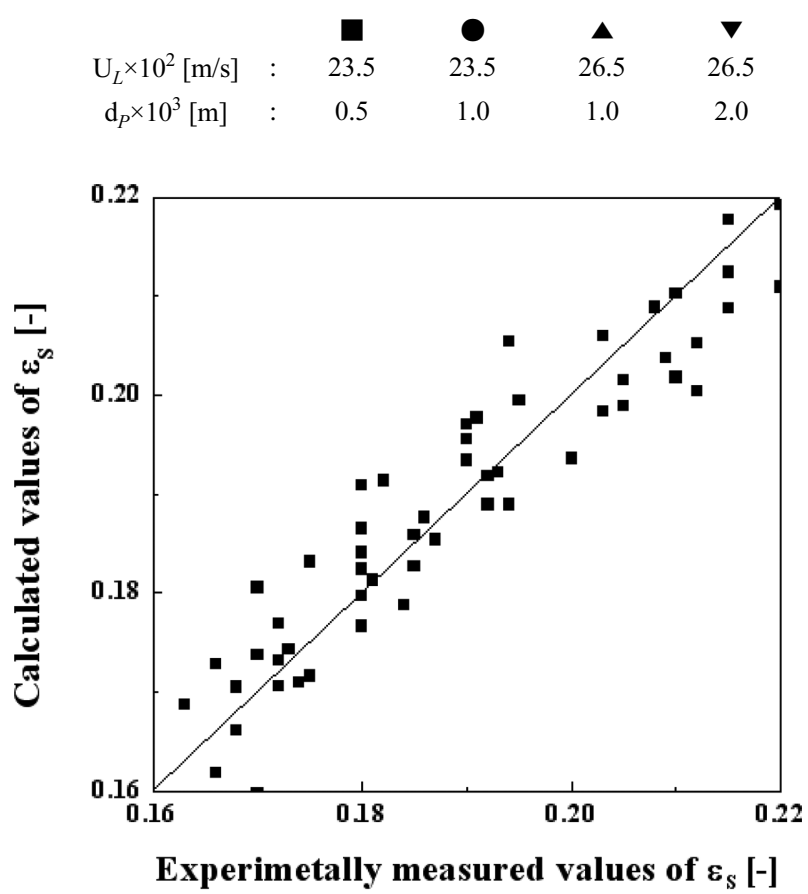

Fig. 11. Correlation of $\varepsilon_{s}$ in terms of operating variables.

the micro scale eddies. That is, the length and velocity of micro eddies can be written as Eqs. (9) and (10), respectively $[22,23]$. Therefore, the contacting frequency of micro eddies can be written as Eq. (11).

$$
\begin{aligned}
& \mathrm{L}_{e}=\left(\frac{\mu_{L}^{3}}{\mathrm{E}_{D} \rho_{L}^{3}}\right)^{0.25} \\
& \mathrm{U}_{e}=\left(\frac{\mathrm{E}_{D} \mu_{L}}{\rho_{L}}\right)^{0.25} \\
& \mathrm{~F}=\mathrm{K} \frac{\mathrm{U}_{e}}{\mathrm{~L}_{e}}=\mathrm{K}\left(\frac{\mathrm{E}_{D} \rho_{L}}{\mu_{L}}\right)^{0.5}
\end{aligned}
$$


In Eq. (11), $\mathrm{K}$ is a constant. It is noted from Eq. (11) that the contacting frequency of micro eddies increases with increasing energy dissipation rate and vice versa. This means that the turbulence intensity in the riser could increase with increasing energy dissipation rate.

The particle holdup in the riser was well correlated in terms of operating variables as Eq. (12), with a correlation coefficient of 0.911 (Fig. 11).

$$
\varepsilon_{S}=0.366 \mathrm{~d}_{P}^{0.203} \mathrm{U}_{L}^{-0.365} \mathrm{G}_{S}^{0.144}
$$

\section{Conclusion}

The holdup of fluidized particles in the riser decreased with increasing liquid velocity, while it increased with increasing particle size or solid circulation rate. The overall particle rising velocity in the riser increased with increasing liquid velocity or solid circulation rate but decreased with increasing particle size. The slip velocity between liquid and particles in the riser increased with increasing liquid velocity or particle size, but it did not change considerably with variation of solid circulation rate. The energy dissipation rate in the riser increased with increasing particle size, solid circulation rate or liquid velocity, due to the increase of contacting frequency between micro eddies. The particle holdup was well correlated with operating variables within the experimental conditions in the present study.

\section{Acknowledgments}

This work was conducted by the financial support of Chungnam National University (2012-1685).

\section{Nomenclatures}

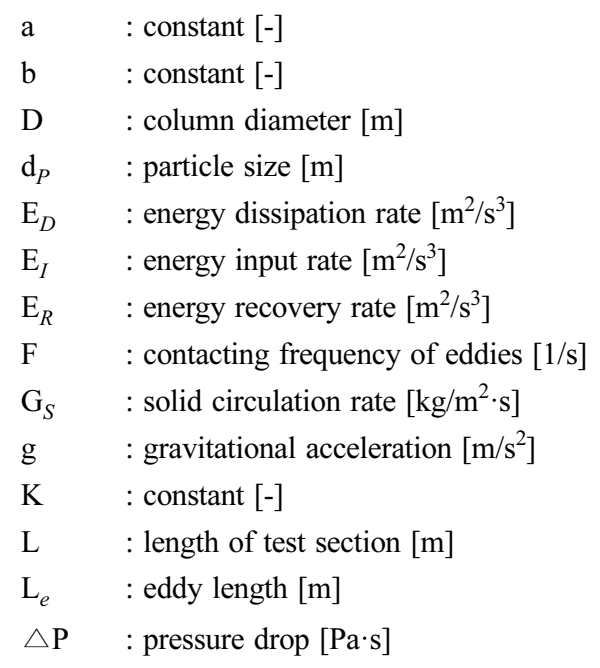

$\mathrm{U}_{e} \quad$ : eddy velocity $[\mathrm{m} / \mathrm{s}]$

$\mathrm{U}_{L} \quad$ : liquid velocity $[\mathrm{m} / \mathrm{s}]$

$\mathrm{U}_{S} \quad$ : overall particle rising velocity $[\mathrm{m} / \mathrm{s}]$

$\mathrm{U}_{\text {slip }} \quad$ : slip velocity $[\mathrm{m} / \mathrm{s}]$

$\mathrm{U}_{t} \quad$ : terminal velocity of particles $[\mathrm{m} / \mathrm{s}]$

\section{Greek Letters}

$\begin{array}{ll}\varepsilon_{L} & \text { liquid holdup [-] } \\ \varepsilon_{S} & \text { particle holdup [-] } \\ \rho_{L} & \text { liquid density }\left[\mathrm{kg} / \mathrm{m}^{3}\right] \\ \rho_{S} & \text { particle density }\left[\mathrm{kg} / \mathrm{m}^{3}\right] \\ \mu_{L} & \text { liquid viscosity }[\mathrm{Pa} \cdot \mathrm{s}]\end{array}$

\section{References}

1. Fan, L. S., Gas-Liquid-Solid Fluidization Engineering, Butterworth, Boston, U.S.A. (1989).

2. Kim, S. D. and Kang, Y., "Dispersed Phase Characteristics in Three-phase Fluidized Beds, Mixed Flow Hydrodynamics, Advances in Engineering Fluid Mechanics,' Gulf Pub. Co., New York, U.S.A (1996).

3. Kim, S. D. and Kang, Y., "Heat and Mass Transfer in Threephase Fluidized-bed Reactor-on Overviews," Chem. Eng. Sci., 52, 3639-3660(1997).

4. Kim, S. D. and Kang, Y., "Hydrodynamics, Heat and Mass Transfer in Inverse and Circulating Three-phase Fluidized-bed Reactors for Waste Water Treatment,' Surf. Sci. Catal., 159, 103108(2006).

5. Kang, Y., Lee, K. I., Shin, I. S., Son, S. M., Kim, S. D. and Jung, H., "Characteristics of Hydrodynamics, Heat and Mass Transfer in Three-phase Inverse Fluidized Beds,' Korean Chem. Eng. Res. (HWAHAK KONGHAK), 46, 451-464(2008).

6. Atta, A., Razzak, S. A., Nigam, K. D. P. and Zhu, J. X., "(Gas)Liquid-Solid Circulating Fluidized Bed Reactors: Characteristics and Applications,' I\&EC Research, 48, 7876-7892(2009).

7. Liang, W. G., Yu, Z. Q., Jin, Y., Wang, Z., Kang, Y., He, M. Y. and Min, E. Z., "Synthesis of Linear Alkylbenzene in a LiquidSolid Circulating Fluidized Bed Reactor,' J. Chem. Technol. Biotechnol., 62, 98-102(1995).

8. Lan, Q., Bassi, A. and Zhu, J. X., "Continuous Protein Recovery From Whey Using Liquid-solid Circulating Fluidized Bed Ionexchange Extraction,' Biotechonol. Bioeng., 78, 157-163(2002).

9. Kuramoto, K., Tsutsumi, A. and Chiba, T., "Model Studies on the Mechanism of Endotoxin Adsorption on Flat-sheet Microfiltration Membrane Adsorbers,' Can. J. Chem. Eng., 77, 921-930 (1999).

10. Zheng, Y. and Zhu, J. X., "The Onset Velocity of a Liquid-solid Circulating Fluidized Bed,' Powder Technol., 114, 244-251(2001).

11. Shin, K. S., Song, P. S., Lee, C. G., Kang, S. H., Kang, Y., Kim, S. D. and Kim, S. J., "Heat-transfer Coefficient in Viscous Liquidsolid Circulating Fluidized Beds,' AIChE J., 51, 671-677(2005).

12. Cho, Y. J., Song, P. S., Lee, C. G., Kang, Y., Kim, S. D. and Fan, L. T., "Liquid Radial Dispersion in Liquid-solid Circulating Fluidized Beds with Viscous Liquid Medium,' Chem. Eng. Common., 192, 257-271(2005). 
13. Patel, A., Zhu, J. and Nakhla, G., "Simultaneous Carbon, Nitrogen and Phosphorous Removal from Municipal Wastewater in a Circulating Fluidized Bed Bioreactor,' Chemosphere., 65, 11031112(2006).

14. Trivedi, U., Bassi, A. and Zhu, J. X., "Continuous Enzymatic Polymerization of Phenol in a Liquid-solid Circulating Fluidized Bed,' Powder Technol., 169, 61-70(2006).

15. Patel, M., Bassi, A. S. and Gomaa, H., "Investigation of a Dualparticle Liquid-solid Circulating Fluidized Bed Bioreactor for Extractive Fermentation of Lactic Acid,' Biotechnol. Prog., 24, 821-831(2008).

16. Lim, D. H., Jang, J. H., Kang, Y. and Jun, K. W., "Flow Behavior of Wakes in a Three-phase Slurry Bubble Column with Viscous Liquid Medium," Korean J. Chem. Eng., 28, 974-979(2011).

17. Lim, D. H., Park, J. H., Kang, Y. and Jun, K. W., "Structure of Bubble Holdups in a Viscous Slurry Bubble Column with Low Surface Tension Media,' Fuel Processing Technol., 108, 2-7(2013).

18. Jin, H. R., Lim, D. H., Lim, H., Kang, Y., Jung, H. and Kim, S.
D., "Demarcation of Large and Small Bubbles in Viscous Slurry Bubble Columns," I\&EC Research, 51, 2062-2069(2012).

19. Jin, H. R., Song, Y. H., Kang, Y., Jung, H. and Lee, H. T., "Holdup Characteristics of Small Bubbles in a Viscous Slurry Bubble Column,' Korean Chem. Eng. Res.(HWAHAK KONGHAK), 49, 8388(2011).

20. Jin, H. R., Lim, H., Lim, D. H., Kang, Y. and Jun, K. W., "Heat Transfer in a Liquid-Solid Circulating Fluidized Bed Reactor with Low Surface Tension Media,' Chinese J. Chem. Eng., 21, 844-849(2013).

21. Lim, H. O., Seo, M. J., Kang, Y. and Jun, K. W., "Particle Fluctuations and Dispersion in Three-phase Fluidized Beds with Viscous and Low Surface Tension Media,' Chem. Eng. Sci., 66, 3234-3242(2011).

22. Deckwer, W. D., "On the Mechanism of Heat Transfer in Bubble Column Reactors,' Chem. Eng. Sci., 35, 1341-1346(1980).

23. Hinze, J. O., Turbulence, McGraw-Hill, New York(1958). 